\title{
ASSOCIATION OF AMNIOTIC URIC ACID, GLUCOSE, LACTATE AND CREATININE CONCENTRATIONS AND LACTATE/CREATININE RATIO WITH NEWBORN SURVIVAL IN SMALL-SIZED DOGS - PRELIMINARY RESULTS
}

\author{
Barbara Bolis $^{1}$, Paola SCARPA ${ }^{1}$, Alessandro RotA ${ }^{2}$, Tiziana Vitiello ${ }^{1}$ \\ and Maria Cristina VERONESI ${ }^{1 *}$ \\ ${ }^{1}$ Department of Veterinary Medicine, Università degli Studi di Milano, via Celoria 10, \\ 20133, Milan, Italy; ${ }^{2}$ Almenno S. Bartolomeo, Bergamo, Italy
}

(Received 16 March 2017; accepted 6 November 2017)

\begin{abstract}
In order to define the normal composition of canine amniotic fluid and to detect differences between surviving and non-surviving newborn puppies, the present study determined the uric acid, glucose, lactate and creatinine concentrations and the lactate to creatinine ratio in amniotic fluids collected during elective Caesarean section from small-sized purebred bitches. The possible relationship between newborn survival and the studied parameters, as well as the effects of maternal parity, fetal gender and Apgar score were assessed. The study enrolled 27 small-sized purebred bitches submitted to elective Caesarean section at term. After opening the fetal membranes, amniotic fluid samples were collected aseptically from the amniotic sac of each fetus. The data obtained from 74 amniotic fluid samples collected from 27 bitches showed that amniotic glucose concentration was lower $(\mathrm{P}<0.05)$ in non-surviving than in surviving puppies. Within the normal, surviving puppies, amniotic glucose concentration was higher $(\mathrm{P}<0.05)$ in male than in female newborns, and the lactate/creatinine ratio was significantly higher in multiparous than in primiparous bitches $(\mathrm{P}<0.05)$. These preliminary results demonstrate the relevance of amniotic glucose, but not of uric acid, lactate, creatinine and the lactate to creatinine ratio for detecting puppies at risk of death immediately after birth.
\end{abstract}

Key words: Dog, amniotic fluid, uric acid, glucose, lactate, creatinine

In mammals, fetal growth, development and well-being are regulated by several factors, and the placenta and fetal fluids contribute to maintaining a suitable environment for the fetus. Amniotic fluid is a very complex and unique fluid that nourishes and protects the fetus, whose composition changes widely along the course of pregnancy as well as in relation to some maternal, fetal or placental

*Corresponding author; E-mail: maria.veronesi@unimi.it; Phone: 0039 (02) 503-18149; Fax: 0039 (02) 503-18148 
imbalances or diseases, and could reflect the metabolism of all the three compartments. In humans, amniotic fluid production is mainly provided by the excretion of fetal urine and by secretions from the respiratory tract and oral cavity (Brace et al., 1994; Underwood et al., 2005), although the gastrointestinal tract and the fetal skin before keratinisation also contribute to the composition of the amniotic fluid (Brace et al., 1994).

In human beings, the analysis of amniotic fluid composition attracted strong scientific interest in the past fifty years; as a result, many aspects were fully investigated and markers for the correct management of both the pregnant women and their fetuses/newborns were identified. In particular, some amniotic parameters near term of pregnancy proved to be useful for the early recognition of disturbances in fetal wellbeing and neonatal outcome in humans (Wiberg-Itzel et al., 2014) as well as in animals (Koski and Fergusson, 1992).

In humans, perinatal asphyxia is a common disorder, regarded as the most important cause of stillbirth and neonatal death (Banupriya et al., 2008). Hypoxia induces an anaerobic metabolism, leading to the release of metabolic degradation products, such as lactic acid (Chen et al., 2000; Liu et al., 2006), coupled with the increased production of hypoxanthine as a result of accelerated ATP degradation and the consequent increased production of purine nucleotides. When this hypoxic condition persists, hypoxanthine is oxidised to xanthine and uric acid (Bader et al., 1995; Akisü and Kültürsay, 1998). A transient, short-term asphyxia is recognised also in dogs during the process of birth, even under normal conditions (Grundy, 2006). It was, however, recognised that during the transition from fetal to neonatal, extrauterine life, hypoxia is transient and ceases within $60 \mathrm{~min}$ after birth (Vassalo et al., 2015). On the other hand, the process of labour in dogs could be very long, so that fetal death can reach very high percentages as compared to other species, especially when dystocia occurs (Moon et al., 2001). In addition, asphyxic puppies are more susceptible to neonatal diseases such as septicaemia, and therefore are at an increased risk of neonatal death (Johnston et al., 2001). Taken together, the birth process and the early neonatal period represent the most challenging stages for canine offspring. Because of the very high percentages of perinatal loss, full knowledge of the normal changes occurring during the last phase of intrauterine fetal development and during the birth process is needed to reduce the impact of canine perinatal death.

As regards early neonatal outcome, besides the risk of perinatal asphyxia, the storage of nutrients and the energy metabolism are recognised as the most important parameters affecting neonatal survival (Vassalo et al., 2015). In humans as well as in animals, the amniotic fluid is swallowed by the fetus, and some of its constituents, such as carbohydrates and proteins, are digested and absorbed by the fetus itself (Pitkin and Reynolds, 1975; Charlton-Char and Rudolf, 1979). Therefore, the amniotic fluid was suggested as a possible source of nutrition for fetal development and growth (Mulvihill et al., 1985). Glucose, recog- 
nised as the major metabolic fuel for the fetus (Battaglia and Meschia, 1978) and for the newborn puppy immediately after birth (Johnston et al., 2001), was shown to be one of the amniotic fluid components in both humans and some animal species. In humans, the condition of intrauterine fetal growth retardation was associated with low glucose concentrations in the amniotic fluid (Drazancić and Kuvacić, 1974). In addition, Koski and Fergusson (1992) reported a positive correlation between amniotic fluid glucose concentrations and fetal weight in rats.

In addition to glucose, other amniotic fluid compounds, such as lactate and uric acid, have been considered as putative indicators of fetal maturity and possible metabolic distress (Cherry et al., 1969). Koski and Fergusson (1992) demonstrated the role of some amniotic fluid constituents as predictors of fetal metabolic status in rats. They found a negative correlation between amniotic uric acid concentrations and fetal weight in rats, while amniotic lactate was not significantly associated with fetal weight. Therefore, it was stated that the measurements of amniotic uric acid could be predictors of fetal growth and metabolic maturity.

Although amniotic fluid lactate concentrations can provide information about fetal acidaemia, Torrance et al. (2013) reported that a normalisation of amniotic fluid volume by calculating the lactate to creatinine ratio was necessary to enable a more accurate estimation of fetal lactacidaemia.

In humans, creatinine is regarded as one of the protein constituents of amniotic fluid, especially towards the term of pregnancy, when it results from the excretory activity of the fetus.

Knowledge of the precise composition of canine fetal fluids is desirable from a scientific point of view and, specifically, the identification of possible markers enabling a better evaluation of the neonate at birth could be very useful from a clinical perspective. In this respect, some parameters proved to be useful for the early prediction of neonatal outcome, metabolic maturity or status in humans, and the use of such parameters would be interesting also for the assessment of newborn dogs.

To the authors knowledge, the normal composition of canine amniotic fluid has received little attention so far. As some amniotic fluid parameters could provide markers for the early prediction of neonatal outcome and/or metabolic status for a better neonatal management also in dogs, the aim of this study was to evaluate the concentrations of some amniotic fluid constituents, such as uric acid (UA), glucose (G), lactate (L), creatinine (CREA) and the lactate to creatinine ratio (L/CREA) in small-sized purebred bitches subjected to elective Caesarean section at term. The possible relationship between the studied parameters and newborn outcome, as well as the possible effects played by maternal parity, newborn gender and Apgar score on UA, G, L, CREA and L/CREA were also evaluated. 
BOLIS et al.

\section{Materials and methods}

\section{Animals}

The study enrolled 7 primiparous (PP) and 20 multiparous (MP) smallsized (body weight $\leq 10 \mathrm{~kg}$ ) purebred bitches, belonging to several breeds (10 Chihuahua, 5 Maltese, 3 Jack Russell Terrier, 2 Toy Poodle, 2 Shih-tzu, 2 Dachshund, 2 Pug and 1 Miniature Bull Terrier), and subjected to elective Caesarean section at term.

Elective Caesarean section was always performed for the health of both the mothers and the puppies, because all the bitches belonged to breeds at high risk of dystocia or had a previous history of problems at parturition. All female dogs were healthy, regularly vaccinated and subjected to parasite prophylaxis, and they were fully monitored from the time of mating (or artificial insemination) throughout the complete gestation length until parturition, as reported by Meloni et al. (2014). Pregnancy diagnosis was performed by ultrasound at 20-28 days after the sole mating, when the estimation of parturition date was also performed by measuring the inner chorionic cavity (Beccaglia and Luvoni, 2006), and fetal viability was assessed by the detection of early fetal cardiac motion (Davidson and Baker, 2009). A further prediction of the parturition date was performed by the ultrasonographic measurement of biparietal diameter at 40-45 days of pregnancy (Beccaglia and Luvoni, 2006), and fetal viability was reevaluated. At the ultrasonographically estimated parturition day, elective Caesarean section was performed on bitches having plasma progesterone (P4) concentrations $\leq 2 \mathrm{ng} / \mathrm{ml}$. For bitches with a plasma P4 still above $2 \mathrm{ng} / \mathrm{ml}$, fetal viability and plasma $\mathrm{P} 4$ concentrations were checked daily until surgery (Meloni et al., 2014).

The study was performed when the national regulations did not require an institutional approval for the use of biological waste materials obtained during routine clinical management of patients. Before the Caesarean section, all the owners signed an informed consent form stating their consent not only to the surgery but also specifically allowing the collection and use of amniotic fluids for research purposes. The anaesthesia was mainly aimed at minimising the negative impact on newborn puppies and was performed according to the same protocol in all the bitches, as reported by Meloni et al. (2014).

\section{Collection of amniotic fluids}

Amniotic fluid samples were collected, after opening the fetal membranes, from the amniotic sac of each fetus in an aseptic manner with a sterile syringe, in which the needle was withdrawn to avoid any possible injury or damage to the fetus (Meloni et al., 2014). Newborn resuscitation and amniotic fluid collection were performed by two separate operators, and amniotic fluid collection never 
affected prompt neonatal care and resuscitation performed by veterinarians particularly skilled in neonatal management (Meloni et al., 2014). The collected amniotic fluids were centrifuged at $1000 \times \mathrm{g}$ for $20 \mathrm{~min}$ and immediately stored at $-20{ }^{\circ} \mathrm{C}$ until analysis for UA, G, L and CREA concentrations, which was always performed within two months of sample collection.

\section{Evaluation of newborn puppies}

Within $5 \mathrm{~min}$ of birth, the neonates were evaluated for viability using the Apgar score (Veronesi et al., 2009), gender and the presence/absence of gross physical malformations, and they were weighed before nursing. Body weight at birth was compared to the breed reference range reported by the Italian Kennel Club (ENCI). Newborn survival was re-checked at $24 \mathrm{~h}$ after birth and at 7 days of age.

\section{Uric acid, glucose, lactate, and creatinine analysis}

After thawing, each fluid sample was re-centrifuged at $1400 \times g$ for $10 \mathrm{~min}$ and the supernatant was assayed for UA, L and CREA by spectrophotometry, using a Cobas Mira Classic automatic analyser (Roche ${ }^{\circledR}$, Basel, Switzerland). Uric acid was analysed by a modified enzymatic colorimetric Trinder [Uric Acid Ben Biochimical Enterprise Srl, Milan, Italy; intra- and inter-assay coefficient of variance (CV) 2.65 and 4.86, respectively; MDC: $0.28 \mathrm{mg} / \mathrm{dl}$ ], lactate was assayed by a colorimetric Trinder (L-Lactate - Ben Biochimical Enterprise Srl, Milan, Italy, intra- and inter-assay CV 1.07 and 1.53 , respectively; MDC: $1.50 \mathrm{mg} / \mathrm{dl}$ ), and creatinine by the modified Jaffé colorimetric, kinetic assay (Creatinine - Hagen Diagnostica Srl, S. Giovanni Valdarno, Italy, intra- and inter-assay CV 2.70 and 5.32, respectively; MDC: $0.09 \mathrm{mg} / \mathrm{dl}$ ). Glucose was analysed by (GODPOD) enzymatic colorimetric method on the basis of the Trinder reaction (Hagen Diagnostica srl, S. Giovanni Valdarno, Italy, intra- and inter-assay CV 2.01 and 3.82, respectively; MDC: $6.97 \mathrm{mg} / \mathrm{dl}$ ).

\section{Statistical analysis}

Data on the amniotic concentrations of UA, G, L and CREA as well as the L/CREA ratio in relation to newborn survival and the possible effect of maternal parity and newborn gender were statistically analysed by a non-parametric ANOVA test (Wilcoxon test), while the possible effect of the Apgar score was assessed using the Kruskall-Wallis test using JMP7 (SAS Inc, Cary, NC). Significance was set for a $\mathrm{P}$ value of $<0.05$. 


\section{Results}

\section{Clinical findings}

From the 27 bitches subjected to elective Caesarean section, a total of 74 puppies were born, 58 from multiparous and 16 from primiparous bitches, 38 females and 36 males; litter size ranged between 1 and 6, with an average of 3.4 puppies per litter. Out of the 74 puppies, 68 (92\%) were normally developed, with an Apgar score $\geq 7$, without gross birth defects, normal weight and surviving at $24 \mathrm{~h}$ and at 7 days of age, while $6(8 \%)$ puppies belonging to different bitches were severely depressed (Apgar score $<4$ ) and did not survive at $24 \mathrm{~h}$ after birth. For the six dead puppies abnormal maternal behaviours or illness were excluded, and necropsy did not reveal gross malformations, trauma or infections.

\section{Amniotic fluid UA, G, L, CREA concentrations and L/CREA ratio}

A total of 68 amniotic fluid samples were collected from normal, surviving newborns, and 6 amniotic fluid samples were collected from the less viable puppies dying within $24 \mathrm{~h}$ after birth. All the 74 amniotic samples were analysed for UA, G, L and CREA concentrations and the L/CREA ratio was calculated.

Although the number of puppies not surviving at $24 \mathrm{~h}$ after birth was low $(n=6)$, a statistical comparison between amniotic fluid UA, G, L and CREA concentrations and L/CREA ratio (median and 25-75 percentiles) in the 68 normal, surviving puppies and in the 6 less viable puppies dead within $24 \mathrm{~h}$ after birth was performed (Table 1).

\section{Table 1}

Uric acid, glucose, lactate and creatinine concentrations and lactate/creatinine ratio (median and 25-75 percentiles) in the 68 amniotic fluid samples collected from normal, surviving puppies and in the 6 amniotic fluid samples collected from puppies dead within $24 \mathrm{~h}$ after birth

\begin{tabular}{lccccc}
\hline & \multicolumn{5}{c}{ Amniotic fluid } \\
\cline { 2 - 6 } & $\begin{array}{c}\text { Uric acid } \\
(\mathrm{mg} / \mathrm{dl})\end{array}$ & $\begin{array}{c}\text { Glucose } \\
(\mathrm{mg} / \mathrm{dl})\end{array}$ & $\begin{array}{c}\text { Lactate } \\
(\mathrm{mg} / \mathrm{dl})\end{array}$ & $\begin{array}{c}\text { Creatinine } \\
(\mathrm{mg} / \mathrm{dl})\end{array}$ & $\begin{array}{c}\text { Lactate/Creatinine } \\
\text { ratio }\end{array}$ \\
\hline $\begin{array}{l}\text { Normal } \\
(\mathrm{n}=68)\end{array}$ & 0.97 & 18 & 72 & 1.7 & 41 \\
$\begin{array}{l}\text { Dead } \\
(\mathrm{n}=6)\end{array}$ & $(0.63-1.56)$ & $(12-30)^{\mathrm{a}}$ & $(53.3-91.2)$ & $(1.1-3.1)$ & $(22.2-63.1)$ \\
\hline
\end{tabular}

${ }^{\mathrm{a}, \mathrm{b}}$ Different superscripts within a column indicate a significant difference $(\mathrm{P}<0.05)$

Data on the median and 25-75 percentiles of amniotic fluid UA, G, L, CREA concentrations measured and L/CREA ratio calculated in the 68 amniotic fluid samples belonging to normal, surviving puppies retrieved from the 27 lit- 
ters, and grouped according to maternal parity and newborn gender are presented in Table 2.

\section{Table 2}

Uric acid, glucose, lactate and creatinine concentrations and lactate/creatinine ratio (median and 25-75 percentiles) in the 68 amniotic fluid samples belonging to normal, surviving puppies, grouped on the basis of maternal parity and newborn gender

\begin{tabular}{lccccc}
\hline & \multicolumn{5}{c}{ Amniotic fluid } \\
\cline { 2 - 6 } & $\begin{array}{c}\text { Uric acid } \\
(\mathrm{mg} / \mathrm{dl})\end{array}$ & $\begin{array}{c}\text { Glucose } \\
(\mathrm{mg} / \mathrm{dl})\end{array}$ & $\begin{array}{c}\text { Lactate } \\
(\mathrm{mg} / \mathrm{dl})\end{array}$ & $\begin{array}{c}\text { Creatinine } \\
(\mathrm{mg} / \mathrm{dl})\end{array}$ & $\begin{array}{c}\text { Lactate/Creatinine } \\
\text { ratio }\end{array}$ \\
\hline $\begin{array}{l}\text { Primiparous } \\
(\mathrm{n}=15)\end{array}$ & 1.2 & 15 & 63 & 2.3 & 25 \\
$\begin{array}{l}\text { Multiparous } \\
(\mathrm{n}=53)\end{array}$ & 0.9 & $(3.5-19.0)$ & $(51.0-85.2)$ & $(1.6-3.5)$ & $(19.0-35.5)^{\mathrm{a}}$ \\
$\begin{array}{l}\text { Males } \\
(\mathrm{n}=33)\end{array}$ & $\begin{array}{c}(1.96) \\
(0.57-1.48)\end{array}$ & $(14.0-30.7)$ & $(59.6-91.2)$ & $(1.1-2.5)$ & $(23.2-66.5)^{\mathrm{b}}$ \\
$\begin{array}{l}\text { Females } \\
(\mathrm{n}=35)\end{array}$ & 0.91 & 25 & 66 & 1.7 & 32 \\
\hline
\end{tabular}

${ }^{a, b}$ Different superscripts within columns indicate significant differences $(\mathrm{P}<0.05)$

In Table 3, data on the median and 25-75 percentiles of amniotic fluid UA, G, L and CREA concentrations measured and L/CREA ratio calculated in the 68 amniotic fluid samples belonging to normal puppies are grouped according to the Apgar score.

Table 3

Uric acid, glucose, lactate and creatinine concentrations and lactate/creatinine ratio (median and 25-75 percentiles) in the 68 amniotic fluid samples belonging to normal, surviving puppies, grouped on the basis of the Apgar score

\begin{tabular}{lccccc}
\hline & \multicolumn{5}{c}{ Amniotic fluid } \\
\cline { 2 - 6 } & $\begin{array}{c}\text { Uric acid } \\
(\mathrm{mg} / \mathrm{dl})\end{array}$ & $\begin{array}{c}\text { Glucose } \\
(\mathrm{mg} / \mathrm{dl})\end{array}$ & $\begin{array}{c}\text { Lactate } \\
(\mathrm{mg} / \mathrm{dl})\end{array}$ & $\begin{array}{c}\text { Creatinine } \\
(\mathrm{mg} / \mathrm{dl})\end{array}$ & $\begin{array}{c}\text { Lactate/Creatinine } \\
\text { ratio }\end{array}$ \\
\hline $\begin{array}{l}\text { Apgar 7 } \\
(\mathrm{n}=14)\end{array}$ & 0.91 & 15 & 62 & 1.7 & 39 \\
$\begin{array}{l}\text { Apgar 8 } \\
(\mathrm{n}=29)\end{array}$ & $(0.63-1.77)$ & $(10.3-18.0)$ & $(43.5-74.3)$ & $(1.1-3.3)$ & $(15.2-56.5)$ \\
$\begin{array}{l}\text { Apgar 9 } \\
(\mathrm{n}=20)\end{array}$ & 1.08 & 19 & 77 & 2.0 & 36 \\
$\begin{array}{l}\text { Apgar 10 } \\
(\mathrm{n}=5)\end{array}$ & $0.83-1.69)$ & $(9-35)$ & $(63.7-97.3)$ & $(1.2-2.8)$ & $(23.3-64.4)$ \\
\hline
\end{tabular}




\section{Discussion}

To the authors' knowledge, as compared to humans, the composition of fetal fluids in dogs is still not completely investigated. Full knowledge of the normal composition of fetal fluids and the identification of some potential markers for the early prediction of neonatal outcome and/or metabolic status for a better neonatal management are thus desirable also in dogs.

A previous study reported glucose, lactate and cortisol concentrations of the amniotic fluid in puppies born by bitches of different size via different types of parturition (Groppetti et al., 2015). However, data on a more homogeneous group and also on some other parameters such as UA, CREA and L/CREA ratio have not been reported yet.

Therefore, the present study was designed to determine the concentrations of UA, G, L and CREA and the L/CREA ratio in amniotic fluid samples collected from newborn puppies, born by elective Caesarean section from healthy, small-sized bitches at term of a normal-course pregnancy, in relation to newborn survival and assessing the possible effect played by maternal parity, neonatal gender and Apgar score on amniotic UA, G, L and CREA concentrations and on the $\mathrm{L} / \mathrm{CREA}$ ratio.

Although the number of puppies dead within $24 \mathrm{~h}$ after birth was low ( $\mathrm{n}=$ 6), a statistical comparison between data obtained on amniotic fluids collected from those puppies and surviving subjects was performed because, according to the implied purpose of the present study, from a clinical perspective it could be useful to identify possible markers for the early prediction of newborn outcome or metabolic imbalance. However, the authors emphasise that these data must be considered only preliminary and deserve further investigations on a higher number of puppies. From this comparison, the most interesting result is the lower (about one-half) median amniotic glucose concentration $(\mathrm{P}<0.05)$ in nonsurviving puppies as compared to newborns surviving at $24 \mathrm{~h}$ and at 7 days of age. However, because two out of these 6 amniotic fluid glucose concentrations were below the minimum detectable concentration, this result must be considered very cautiously, and further studies are needed to define the real amniotic fluid glucose concentrations in puppies at risk of death immediately after birth.

However, it seems reasonable to suppose that amniotic fluid glucose concentrations in non-surviving puppies could be much lower than those found in surviving puppies. As the 6 dead puppies showed a normal birth weight for the given breed, it seems possible to hypothesise that the low amniotic fluid glucose concentrations could be the cause, or the effect, of metabolic imbalance at the time of birth, and could be suspected as at least one of the causes of death. However, even if no significant differences were found for the other studied parameters, based on these very preliminary results, it is not possible to exclude the involvement of other factors responsible for the impairment of neonatal adaptation. 
In a previous study (Groppetti et al., 2015), mean glucose concentrations of the amniotic fluid were found to be lower $(14.2 \pm 0 \mathrm{mg} / \mathrm{dl})$ than in puppies alive at $48 \mathrm{~h}$ after birth $(20.4 \pm 9.1 \mathrm{mg} / \mathrm{dl})$.

The median amniotic fluid glucose concentrations in surviving puppies $(18 \mathrm{mg} / \mathrm{dl})$ were similar to the mean value $(20.4 \mathrm{mg} / \mathrm{dl})$ reported by Groppetti et al. (2015), while in dead puppies the median glucose concentrations in the present study were lower than the mean value reported by the above authors ( 7 vs. $14.2 \mathrm{mg} / \mathrm{dl})$.

Although the data were obtained from a small number of puppies, the lack of significant differences in UA, L, CREA concentrations and L/CREA ratio between surviving and non-surviving puppies is interesting and seems to suggest that asphyxia and renal maturity could be less important than glucose as a metabolic fuel, for the early survival of puppies.

When data obtained on the 68 amniotic fluid samples collected from normal, surviving puppies were considered in relation to the Apgar score, no significant association was found between the studied parameters and the Apgar score, in agreement with the results reported by Groppetti et al. (2015).

Within the group of surviving puppies, the overall median concentration of UA $(0.97 \mathrm{mg} / \mathrm{dl})$ was lower than the concentrations reported in amniotic fluid samples collected in normal human pregnancies at term $(5.8 \pm 1.2 \%)$ (Cherry et al., 1969), and difficult to compare to data reported by Fresno et al. (2012) in cats at term $(<5 \mathrm{mg} / \mathrm{dl})$. No effect of maternal parity, newborn gender and Apgar score was observed on amniotic fluid UA concentrations.

The overall median glucose concentration of the amniotic fluid $(18 \mathrm{mg} / \mathrm{dl})$ was very similar to data reported for amniotic mean glucose in human normal pregnancies (22 $\pm 12 \mathrm{mg} / \mathrm{dl}$ ) (Mohajeri Tehrani et al., 2009) but lower than mean glucose concentrations of the amniotic fluid $(69 \mathrm{mg} / \mathrm{dl})$ reported for cats at 60 days of pregnancy (Fresno et al., 2012). Although no differences were found depending on maternal parity and Apgar score, median glucose concentrations of the amniotic fluid were, surprisingly, significantly higher $(\mathrm{P}<0.05)$ in male than in female puppies ( $25 \mathrm{vs.} 15 \mathrm{mg} / \mathrm{dl}$, respectively). Such a difference has not been reported in humans and was not investigated in cats by Fresno et al. (2012), and by Groppetti et al. (2015) in newborn dogs. Koski and Fergusson (1992) reported that amniotic fluid glucose concentration might predict metabolic maturity; so, as in the present study all the newborns were healthy and viable, and survived at $24 \mathrm{~h}$ and at 7 days of age, it seems possible to suggest that female puppies could be considered to have 'lower' metabolic maturity than males.

The overall median lactate concentration of the amniotic fluid (72 mg/dl) was slightly higher than that reported for humans during normal labour $(7.1 \pm$ $1.45 \mathrm{mmol} / \mathrm{L}$, corresponding to $64 \pm 13.06 \mathrm{mg} / \mathrm{dl}$ ) (Korenovsky et al., 2013), but lower in comparison to data $(12.5 \mathrm{mmol} / 1$, corresponding to $112.6 \mathrm{mg} / \mathrm{dl})$ reported for late-pregnant cats by Fresno et al. (2012). The amniotic fluid lactate con- 
centrations were also studied in horses (Pirrone et al., 2012), and the mean concentrations reported for foals born from spontaneous eutocic parturition were higher $(14.47 \mathrm{mmol} / \mathrm{L}$, corresponding to $130.36 \mathrm{mg} / \mathrm{dl})$ in comparison to data observed in the present study in dogs born by elective Caesarean section. The lower amniotic fluid lactate concentrations observed in the present study in dogs in comparison to data reported for horses were, however, not unexpected. In fact, in the present study, dogs were subjected to elective Caesarean section before the start of labour, while data reported for horses were obtained in amniotic fluid samples collected during spontaneous parturition, when foaling had already started. However, it is interesting to note that the amniotic fluid lactate concentrations in dogs were slightly higher than data reported for women during normal labour, suggesting, besides a species-specific effect, also an effect played by the type of parturition. The mean lactate concentration of the amniotic fluid in puppies born by elective Caesarean section, as reported by Groppetti et al. (2015) $(8.7 \pm 3.4 \mathrm{mmol} / \mathrm{l}$, corresponding to $78 \pm 30.6 \mathrm{mg} / \mathrm{dl})$, was very similar to the median values found in the present study. In horses, a negative correlation was found between amniotic fluid lactate concentrations and parity. In the present study, no effects of maternal parity, newborn gender and Apgar score on lactate concentrations of the amniotic fluid were found.

The overall median creatinine concentration was $1.7 \mathrm{mg} / \mathrm{dl}$, very similar to data reported in humans under normal conditions $(1.9 \pm 1.5 \mathrm{mg} / \mathrm{dl})$ (Cherry et al., 1969), but lower than creatinine concentrations demonstrated by Fresno et al. (2012) for cats at 60 days of pregnancy $(<10 \mathrm{mg} / \mathrm{dl})$. Creatinine output is regarded as a good indicator of renal function and glomerular filtration rate, and its reduced concentration in human amniotic fluid is associated with maternal diabetes mellitus and toxaemia. In the present study, the CREA concentrations of the amniotic fluid were supposedly related to the presence of fetal urine also in the amniotic compartment, due to the final intrauterine development of the urinary system and the deviation of fetal urine from the allantoic sac toward the amniotic compartment through the urethra as the urachus is progressively occluded (Fresno et al., 2012). However, the percentile values seem to suggest that, based upon the results of the present study, a rather wide range of CREA levels in the amniotic fluid should be regarded as indicative of normal maternal and fetal conditions in dogs. Unfortunately the statistical analysis failed to detect differences in creatinine concentrations of the amniotic fluid according to maternal parity, newborn gender and Apgar score, and therefore other parameters should be investigated in order to determine the factors that could contribute to this wide range of normal CREA concentrations of the amniotic fluid in dogs.

According to Torrance et al. (2013), the lactate concentration of the amniotic fluid was normalised by the calculation of the L/CREA ratio to enable a better evaluation of fetal lactacidaemia. In the present study, the overall L/CREA ratio was 41 , and no significant difference was found according to newborn gender 
or Apgar score. As expected, also this ratio showed a rather wide range of percentiles and, as a consequence, a wide range of normality. A higher L/CREA median ratio in the amniotic fluid collected from puppies born by multiparous in comparison to primiparous bitches (46 vs. 25 , respectively) was found, but the biological meaning of this finding deserves further investigations.

In conclusion, data from the present study show that, in purebred smallsized dogs, amniotic fluid glucose concentrations could represent a suitable parameter for the identification of puppies at risk of death within $24 \mathrm{~h}$ after birth, while lactate and creatinine concentrations and the lactate to creatinine ratio do not seem to play a relevant role. Within the group of normal, surviving puppies, lower amniotic glucose concentrations were found in female than in male puppies, while a higher lactate to creatinine ratio was found in the amniotic fluids of puppies born by multiparous bitches compared to those delivered by primiparous dams. However, the wide ranges observed for each parameter, suggesting a wide inter-individual variation, require further investigation to identify the factors affecting this wide range of normality.

\section{References}

Akisü, M. and Kültürsay, N. (1998): Value of the urinary uric acid to creatinine ratio in term infants with perinatal asphyxia. Acta Paediatr. Jpn. 40, 78-81.

Bader, D., Gozal, D., Weinger-Abend, M., Berger, A. and Lanir, A. (1995): Neonatal urinary uric acid/creatinine [correction of ceratinine] ratio as an additional marker of perinatal asphyxia. Eur. J. Pediatr. 154, 747-749.

Banupriya, C., Ratnakar, Dourerdjou P., Mondal, N., Vishnu, B. and Koner, B. C. (2008): Can urinary excretion rate of malondialdehyde, uric acid and protein predict the severity and impending death in perinatal asphyxia? Clin. Biochem. 41, 968-973.

Battaglia, F. C. and Meschia, G. (1978): Principal substrates of fetal metabolism. Physiol. Rev. 58, 499-527.

Beccaglia, M. and Luvoni, G. C. (2006): Comparison of the accuracy of two ultrasonographic measurements in predicting the parturition date in the bitch. J. Small Anim. Pract. 47, 670-673.

Brace, R. A., Wlodek, M. E., Cock, M. L. and Harding, R. (1994): Swallowing of lung liquid and amniotic fluid by the ovine fetus under normoxic and hypoxic conditions. Am. J. Obstet. Gynecol. 171, 764-770.

Charlton-Char, V. and Rudolf, A. (1979): Digestion and absorption of carbohydrates by the fetal lamb in utero. Pediatr. Res. 13, 1018-1023.

Chen, H. J., Yau, K. I. T. and Tsai, K. S. (2000): Urinary uric acid/creatinine ratio as an additional marker of perinatal asphyxia. J. Formos. Med. Assoc. 99, 771-774.

Cherry, S. H., Dolger, H., Rosenfield, R. E. and Kochwa, S. (1969): Amniotic fluid urea nitrogen, uric acid, and creatinine in diabetic pregnancies. Bull. New York Acad. Med. 45, 46-52.

Davidson, A. P. and Baker, T. W. (2009): Reproductive ultrasound of the bitch and queen. Top. Companion Anim. Med. 24, 55-63.

Drazancić, A. and Kuvacić, I. (1974). Amniotic fluid glucose concentration. Am. J. Obstet. Gynecol. 120, $40-48$. 
Fresno, L., Rodriguez-Gil, J. E., Rigau, T., Pastor, J. and Rivera del Alamo, M. M. (2012): Modulation of the biochemical composition of amniotic and allantoic fluids as a control mechanism of feline foetal development. Placenta 33, 522-527.

Groppetti, D., Martino, P. A., Ravasio, G., Bronzo, V. and Pecile, A. (2015): Prognostic potential of amniotic fluid analysis at birth on canine neonatal outcomes. Vet. J. 206, 423-425.

Grundy, S. A. (2006): Clinically relevant physiology of the neonate. Vet. Clin. North Am. Small Anim. Pract. 36, 443-459.

Johnston, S. D., Root Kustritz, M. V. and Olson, P. S. (2001): The neonate - from birth to weaning. In: Canine and Feline Theriogenology. Saunders, Philadelphia. pp. 146-167.

Korenovsky, Yu. V., Chugunova, T. N., Filchakova, O. N., Sinelnikova, L. M., Shabalina, Yu. V. and Elchaninova, S. A. (2013): Lactate concentration in amniotic fluid at early neonatal period in perinatal hypoxia. Kazanskiy Meditsinskiy Zhurnal 5, 704-706.

Koski, K. G. and Fergusson, M. A. (1992): Amniotic fluid composition responds to changes in maternal dietary carbohydrate and is related to metabolic status in term fetal rats. J. Nutr. 122, 385-392.

Liu, L., Zhou, H. Y., Song, J. W., Nie, W. X. and Su, Z. Y. (2006): Measurement of urinary S100B protein levels and lactate/creatinine ratio in early detection of neonatal hypoxic-ischemic encephalopathy. World J. Pediatr. 4, 270-275.

Meloni, T., Comin, A., Rota, A., Peric, T., Contri, A. and Veronesi, M. C. (2014): IGF-I and NEFA concentrations in fetal fluids of term pregnancy dogs. Theriogenology 81, 1307-1311.

Mohajeri Tehrani, M., Amini Moghaddam, S., Annabestani, Z., Heshmat, R., Alyasin, A., Aghaie Meibodi, H. and Larijani, B. (2009): Amniotic fluid, maternal, and neonatal serum Cpeptide as predictors of macrosomia: A pilot study. J. Diabetes Metab. Disord. 8, 129-136.

Moon, P. F., Massat, B. J. and Pascoe, P. J. (2001): Neonatal critical care. Vet. Clin. North Am. Small Anim. Pract. 31, 343-366.

Mulvihill, S. J., Stone, M. M., Debas, H. T. and Fonkalsrud, E. W. (1985): The role of amniotic fluid in fetal nutrition. J. Pediatr. Surg. 20, 668-672.

Pirrone, A., Mariella, J., Gentilini, F. and Castagnetti, C. (2012): Amniotic fluid and blood concentrations in mares and foals in the early postpartum period. Theriogenology 78, 1182-1189.

Pitkin, R. M. and Reynolds, W. A. (1975): Fetal ingestion and metabolism of amniotic fluid protein. Am. J. Obstet. Gynecol. 123, 356-363.

Torrance, H. L., Pistorius, L., Voorbij, H. A. and Visser, G. H. (2013): Lactate to creatinine ratio in amniotic fluid: a pilot study. J. Matern. Fetal Neonatal Med. 26, 728-730.

Underwood, M. A., Gilbert, W. M. and Sherman, M. P. (2005): Amniotic fluid: not just fetal urine anymore. J. Perinatol. 25, 341-348.

Vassalo, F. G., Simões, C. R., Sudano, M. J., Prestes, N. C., Lopes, M. D., Chiacchio, S. B. and Lourenco, M. L. (2015): Topics in the routine assessment of newborn puppy viability. Top. Companion Anim. Med. 30, 16-21.

Veronesi, M. C., Panzani, S., Faustini, M. and Rota, A. (2009): An Apgar scoring system for routine assessment of newborn puppy viability and short-term survival prognosis. Theriogenology 72, 401-407.

Wiberg-Itzel, E., Pembe, A. B., Wray, S., Wihlbäck, A. C., Darj, E., Hoesli, I. and Åkerud, H. (2014): Level of lactate in amniotic fluid and its relation to the use of oxytocin and adverse neonatal outcome. Acta Obstet. Gynecol. Scand. 93, 80-85. 